\title{
The Economic Impact of German Pig Carcass Pricing Systems and Risk Scenarios for Boar Taint on the Profitability of Pork Production with Immunocastrates and Boars
}

\author{
Kevin Kress ${ }^{1, *}$ and Mandes Verhaagh ${ }^{2, *}$ \\ 1 Department of Behavioral Physiology of Livestock, Institute of Animal Science, University of Hohenheim, \\ Garbenstraße 17, 70599 Stuttgart, Germany \\ 2 Thünen Institute of Farm Economics, Bundesallee 63, 38116 Braunschweig, Germany \\ * Correspondence: kress.kevin@uni-hohenheim.de (K.K.); mandes.verhaagh@thuenen.de (M.V.); \\ Tel.: +49-711-459-22536 (K.K.); Tel.: +49-531-596-5119 (M.V.)
}

Received: 6 August 2019; Accepted: 16 September 2019; Published: 18 September 2019

\begin{abstract}
From 2021 onwards, surgical castration of male piglets without pain relief will be banned in Germany. In Europe, stakeholders have committed themselves to end piglet castration from 2018 onwards. Alternatives to surgical castration are pork production with boars or immunocastrates. The competitiveness of these production systems is required to increase their market acceptance. The aim of this study was to test the profitability of pork production with boars and immunocastrates under different carcass pricing systems and penalty systems linked to boar taint. The calculations were based on the performance parameters of 36 animals ( $n=12$ immunocastrates, $n=12$ boars, $n=12$ barrows) from an experimental study. In order to analyze the economic effects of both alternatives under different regional German production systems, the performance data were set in relation to the data of agri benchmark. Both boars and immunocastrates performed economically worse than barrows in all the scenarios tested. If immunocastrates are sold according to the boar pricing system, the profitability of this technique is even lower, but still more profitable than boar fattening. Pork production with boars is the most unprofitable alternative in this study and will be further devalued if a penalty system linked to boar taint will be introduced.
\end{abstract}

Keywords: immunocastration; boars; surgical castration; carcass pricing systems; boar taint; risk scenarios; pork production; profitability; pork market; androstenone; skatole

\section{Introduction}

For German pork production, about $80 \%$ of all male piglets are surgically castrated within their first week of life [1,2]. Consumers evaluate surgical castration without pain-relieving methods very critically [3]. In September 2009, this led German stakeholders of the pork chain to commit to the goal of ending surgical castration of piglets in the so-called 'Düsseldorfer Erklärung' [4]. These developments have also resulted in an amendment of the German animal protection law in 2013. From January 2019, piglet castration without anesthesia or analgesia was to be outlawed. Contrary to the planned change in the law, the government of the Federal Republic of Germany agreed in November 2018 to postpone the implementation of the amendment by 2 years [5]. As its reason, the German government stated that there are no competitive alternatives available, and that a prohibition of surgical castration without pain-relief could have a negative impact on German pig production [6].

Alternatives to surgical castration are pork production with boars or with immunocastrates $[7,8]$. Although these procedures are available in practice, their market shares are low. In Germany, about 
$20 \%$ of male pigs are fattened as boars, and less than $1 \%$ as immunocastrates [1]. The acceptance of pork production with boars is limited because of the risk of unpleasant boar taint in the carcass, which can be ascribed to an excessive accumulation of the compounds androstenone and skatole $[9,10]$. A large part of the population is sensitive to skatole above a threshold of $0.25 \mu \mathrm{g} / \mathrm{g}$ liquid fat $[10,11]$. Because of a genetic polymorphism, only a lower proportion of the population is sensitive to androstenone above a threshold of $0.5-1.0 \mu \mathrm{g} / \mathrm{g}$ in liquid fat $[10,12]$. What both compounds have in common is that most consumers who are sensitive to these compounds dislike them [13]. In order to sort out boar-tainted meat, carcasses of boars are currently evaluated at the slaughter line by the human nose test [14]. However, under commercial conditions at the slaughter line, the reproducibility of valid results is only $23 \%$, so it is highly likely that boar-tainted pork will be undetected and reaches consumers [15]. Objective at-line methods of detecting androstenone- and skatole-tainted carcasses have been developed and have a high potential for being implemented for commercial use at the slaughter line under real-time conditions [16]. However, commonly accepted thresholds for boar taint compounds to exclude tainted pork from the fresh meat market do not exist. Some research has been done to evaluate possibilities of using tainted pork with skatole levels up to $0.3 \mu \mathrm{g} / \mathrm{g}$ liquid fat and very high androstenone values above $3.5 \mu \mathrm{g} / \mathrm{g}$ liquid fat for processing, after blending it with meat from barrows or gilts [17]. However, the processing characteristics of pork from boars are unfavorable because of a higher proportion of polyunsaturated fatty acids, which makes it unsuitable for processing traditional dry-cured products [18].

Immunocastration is an active immunization against the hormone GnRH (Gonadotropin-releasing hormone) by vaccinating the boars twice with the vaccine Improvac@(Zoetis Inc., Parsippany, New Jersey, US). After the second vaccination, the secretion of LH (Luteinizing hormone) is reduced and testicular functions cease temporarily, so that from a physiological point of view the animals are barrows, with similar behavioral, metabolic, and meat quality characteristics. Immunocastration can therefore reliably prevent boar taint and can be regarded as a sustainable alternative to surgical castration and pork production with boars that meets animal welfare aspects as well as pork market requirements. Improvac $囚 i s$ licensed for commercial use in Europe with no technical or legal limitations and can be used for conventional as well as for organic pork production. Knowledge gaps on the potentials of this technique within the value chain prevent a more extensive market relevance [19]. Producing boars or immunocastrates can also be very attractive and cost-effective from an economic point of view [6], since the feed efficiency of boars and immunocastrates is higher than that of barrows [20,21]. In Germany, there are different carcass pricing systems for boars and barrows. It is currently unclear to which pricing system immunocastrates will be assigned, even though this is crucial for economic efficiency [6]. In addition, it is still unclear what effects a quantification of androstenone and skatole values at the slaughter line will have on the profitability of pork production with boars or immunocastrates, and on the use of boar-tainted meat. Penalty systems linked to boar taint are already used in France and Norway, and are likely to be also implemented in other European countries as market shares of boars and immunocastrates increase [14]. In order to enable a sustainable production of boars or immunocastrates in Germany, both alternatives must be critically analyzed under different economic scenarios by using risk scenarios for boar taint and evaluating immunocastration under different pricing systems.

\section{Materials and Methods}

\subsection{Animal Performance Data}

The study was performed at the experimental unit of the University of Hohenheim (Unterer Lindenhof 2572800 Eningen, Germany) between November 2017 and August 2018 as part of the SuSi project (ERA-NET SusAn). Two consecutive trials were conducted in total with 36 male pigs (F1 German Landrace $\times$ Pietrain; 18 animals per trial), which were assigned to three treatment groups: immunocastrates (IC, $n=12)$, boars ( $\mathrm{B}, n=12)$, and barrows (BA, $n=12)$. The animals were about 
10 weeks of age at the beginning of the study and were housed in groups of six animals under standard conditions ( $1.2 \mathrm{~m}^{2}$ per pig, solid floor). Animals were fed ad libitum with three different feed compositions, as given in Table 1 . In all pens, $500 \mathrm{~g}$ of chopped straw and $1000 \mathrm{~g}$ of sawdust were supplied daily. Feed intake was recorded per pen. Individual weight was determined at day of birth, after 21 days, at the start of the study (age $=10$ weeks), and three times during the fattening period corresponding to the end of the three feeding periods (week 17, 21, and 27/28). The animals were part of a physiological study with repeated blood sampling, and the experiment was approved by the ethical committee of the regional council of Tuebingen (Baden-Wuerttemberg, Germany) with number 47/17 TH. Thus, the number of animals in this study is lower than in field studies without frequent sampling. The number of animals and the assignment of individuals to different treatment groups and housing groups (standard and experimental) were carried out randomly according to the method of 'Latin Squares'. For the present study, only the animals under standard housing conditions were analyzed.

Table 1. Feeding periods and feed compositions (ME: metabolizable energy; CP: crude protein; DM: dry matter).

\begin{tabular}{ccccc}
\hline Feeding Period & Age (weeks) & ME (MJ) & CP (\%) & DM (\%) \\
\hline 1 & $10-17$ & 13.13 & 17.51 & 87.54 \\
2 & $17-21$ & 13.15 & 16.14 & 87.49 \\
3 & $21-27 / 28$ & 12.41 & 15.9 & 87.85 \\
\hline
\end{tabular}

BA were surgically castrated during the first week of life without anesthesia but received $0.2 \mathrm{~mL}$ Metacam $囚$ (Meloxicam, $5 \mathrm{mg} / \mathrm{mL}$ ) as post-surgery pain relief. IC received two applications of the vaccine Improvac®at an average age of 12 (V1-first vaccination) and 22 weeks (V2-second vaccination). The timeline of the experimental procedure is given in Figure 1. All pigs were slaughtered on two slaughter dates per trial at an age of either 27 or 28 weeks at an experimental slaughter facility (LSZ Boxberg, Seehöfer Straße 50, 97944 Boxberg). Hot carcass weights were recorded and fat samples from the neck area were collected for the measurements of androstenone (A) and skatole (S). Both were analyzed using HPLC as described by Batorek-Lukač and co-authors [22].

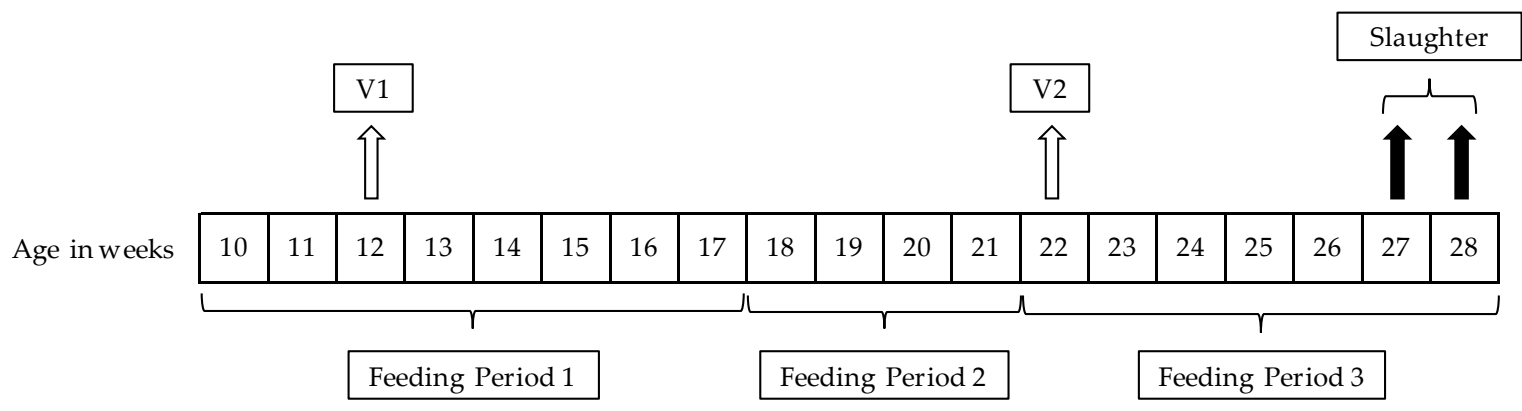

Figure 1. Generalized timeline of the trials (feeding periods, vaccination times (V1, V2), and slaughter dates according to the age (weeks) of the animals).

\subsection{Generating Economic Data of Typical German Pig Fattening Farms for Modelling}

The analysis of the economic effects of the different production systems with barrows, immunocastrates, or boars was conducted with data from so-called 'typical farms' of the international agri benchmark network [23]. This data concept describes representative regional farms, which are constructed from the data sets of several real farms, and evaluated for plausibility by an expert group [24]. The results show the typical economic situation of a common farming business type in a region [25]. For the calculations, all changes and effects on the existing production process had to be identified, specified, quantified and the economic effects analyzed in cooperation with the 
aforementioned expert group [6]. The evaluation of the economic indicators was based on the TIPI-CAL model. TIPI-CAL is a production and accounting model that provides a detailed representation of the production technology and the physical interrelationships in farms. It is a deterministic, recursive, and dynamic simulation model for various farm sectors and can basically map a 10 year period including trends of all output variables [26]. Thus, a full cost accounting for the business model of the typical regional farm is possible. On this basis, changes in the production process (e.g., boar fattening, immunocastration) can be predicted for the profitability of the whole farm. The typical farms were surveyed according to a standardized protocol, as described by Verhaagh and co-authors [23]. In short, a focus group consisting of a consultant and three to six participants from operating enterprises for each region were included to guarantee a valid data basis. The focus group was organized as a round table discussion in which all necessary operating data were collected on the basis of a standardized questionnaire by Verhaagh [23]. The focus group formed a consensus on each parameter in order to describe what a typical enterprise would look like, instead of adopting average values of participating producers. The data basis of typical German pig fattening farms is updated annually in cooperation with a focus group whose experts are familiar with the regional circumstances of pig producing farms. For this study, the five most important pig fattening regions of Germany were selected (see total number of pigs below) and the necessary operating parameters were included (see Table 2). All typical farms used in this study were specialized farms for pig fattening.

Table 2. Key figures for typical German pig fattening farms-baseline scenario [27].

\begin{tabular}{ccccc}
\hline Farm & Region & $\begin{array}{c}\text { Number of Pigs } \\
\text { Sold (per year) }\end{array}$ & $\begin{array}{c}\text { Fattening } \\
\text { Places }\end{array}$ & $\begin{array}{c}\text { Production Principle } \\
\text { (All in-All out) }\end{array}$ \\
\hline DE_0_3600 & Lower Saxony & 3.628 & 1.320 & Pen \\
DE_0_3800 & Bavaria & 3.758 & 1.472 & Pen \\
DE_0_5000 & North & 5.220 & 1.850 & Pen \\
DE_0_6000 & Lower Saxony & 5.941 & 2.100 & Barn \\
DE_0_6300 & Schleswig-Holstein & 6.228 & 2.000 & Barn \\
\hline \multirow{2}{*}{ Farm } & Live Weight at & Dressing & Hot Carcass & Price (EUR per kg Hot \\
& Slaughter (kg) & Percentage (\%) & Weight (kg) & Carcass Weight) \\
\hline DE_0_3600 & 121 & 79 & 95.3 & 1.68 \\
DE_0_3800 & 123 & 80 & 98.4 & 1.63 \\
DE_0_5000 & 121 & 79 & 95.6 & 1.60 \\
DE_0_6000 & 123 & 80 & 97.8 & 1.76 \\
DE_0_6300 & 122 & 78 & 95.2 & 1.60 \\
\hline
\end{tabular}

\subsection{Economic Risk Scenarios and Pig Carcass Pricing Systems}

The scenario specifications of typical German pig fattening farms were adjusted with the data from the experiment on the basis of different boar taint risk scenarios and different German carcass pricing systems for pigs. First, performance parameters (average daily gain-ADG) from the trial were used in the calculations for the typical farms. The gradient curves of the three treatment groups (IC, $\mathrm{B}$, and BA) were derived from the experimental data. As each typical farm had individual process ranges (weight at the beginning and end of the fattening period), the gradient curves of the trial were adjusted to the respective typical farms. This resulted in new gradient curves for all typical farms, as the process ranges of the trial were different to those of the baseline. In the next step, the ADG of BA was set in relation to the ADG of IC and $B$ and then set in relation to the baseline, which resulted in the final gradient curves and performance parameters (ADG) for all typical farms. The relative changes in feed conversion ratio (FCR) was also derived from the trials and set in relation to the typical farms.

In addition, literature data was also used for estimating several cost factors, such as the additional working time changes (IC: +0.79 min per animal; B: +1.2 min per animal; additional costs for sex-separate housing, application of vaccination, and more intensive observation of animals), the costs 
for Improvac $₫(3.59$ EUR per animal for both vaccinations), and the costs for removing the testes at the slaughter line (0.64 EUR per male pig) [28]. The costs are not offset by the value of the testicles for any other use. In order to analyze the impact of different pricing systems on the profitability of immunocastration and boar fattening, the pricing system for boars and barrows used was that of the German pork market leader, Tönnies Holding ApS \& Co. KG [29]. The values for live weight at slaughter were taken from the baseline (Table 2) and the dressing percentages derived from the experiment (B: $80.27 \%$, IC: $80.17 \%$, and BA: $82.54 \%$ ). They were then set in relation to the values from the baseline (Table 2). For the evaluation of carcasses, the parts of the carcass (ham, loin, and belly weight) were estimated on the basis of the Auto-FOM III formula [30]. Historical slaughter data of boars and barrows were used for the belly meat percentage (B: $61.72 \%$ and BA: $57.65 \%$ ) [29]. For IC, the mean value of the belly lean meat percentage of boars and barrows was calculated (IC: $59.69 \%$ ), as the lean meat content of immunocastrates lies between boars and barrows [21] and lean meat content correlates significantly with the belly lean meat percentage $(p=0.92)$ [31]. The base prices in EUR per $\mathrm{kg}$ hot carcass weight from Table 2 were used for the calculations. BA were only priced based on the barrow pricing system, and for B only on the basis of the pricing systems for boars. IC prices were calculated both under the barrow pricing system with and without the additional costs for removing the testes, and again under the boar pricing system. In addition, the occurrence of boar taint was economically evaluated. For this, androstenone (A) and skatole (S) values were also included to create various risk scenarios depending on the intensity of boar taint (see Table 3). For the respective risk scenarios, carcasses with values of boar taint compounds above a certain threshold were valued at the 0 EUR minimum. Furthermore, a proportion of $3.5 \%$ was subtracted from the boar tainted carcasses above a certain threshold, as $3.5 \%$ of all carcasses are already discounted as being affected by boar taint in the boar pricing system [28].

Table 3. Risk scenarios and thresholds for boar taint compounds in adipose tissue from the neck area.

\begin{tabular}{lccccc}
\hline Scenario & $\mathbf{1}$ & $\mathbf{2}$ & $\mathbf{3}$ & $\mathbf{4}$ & $\mathbf{5}$ \\
\hline Boar taint compounds & $\mathrm{S}^{1}$ & $\mathrm{~A}^{1}$ & $\mathrm{~A}^{1}$ & $\mathrm{~A}^{1}$ & $\mathrm{~A}^{1}$ \\
\hline Threshold & 0.25 & 0.5 & 1 & 2 & 5 \\
\hline \multicolumn{7}{r}{$\mu \mathrm{g}$ per g liquid fat. }
\end{tabular}

\section{Results}

\subsection{Performance Data of the Trials in Relation to Typical German Pig Fattening Farms}

In all typical German pig fattening farms, the ADG of immunocastrates is lower than the baseline scenario (see Table 4). Although after the second vaccination (ADG-Period 3) the ADG of IC was higher than that of BA (see Table S1), over the total fattening period, the ADG in BA was higher in all typical farms because feeding period 3 was too short to compensate ADG disadvantages of the previous feeding periods. The FCR of IC was more than 7\% lower in all typical farms and therefore more efficient than the FCR of the baseline. Because of the higher ADG of BA compared to IC, the fattening period of IC was longer in all typical fattening farms than in the baseline.

Table 4. Impact of immunocastration on performance data of typical German pig fattening farms in relation to the baseline (barrows).

\begin{tabular}{ccccccc}
\hline Farm & ADG IC (g) & $\Delta$ ADG IC (\%) & FCR IC & $\Delta$ FCR IC (\%) & $\begin{array}{c}\text { Fattening } \\
\text { Period IC (days) }\end{array}$ & $\begin{array}{c}\Delta \text { Fattening } \\
\text { Period IC (days) }\end{array}$ \\
\hline DE_0_3600 & 821 & -1.18 & 2.61 & -7.12 & 110.3 & +1.3 \\
DE_0_3800 & 763 & -0.61 & 2.57 & -7.22 & 120.7 & +0.7 \\
DE_0_5000 & 805 & -1.33 & 2.61 & -7.44 & 115.5 & +1.5 \\
DE_0_6000 & 788 & -1.04 & 2.70 & -7.22 & 121.3 & +1.3 \\
DE_0_6300 & 868 & -0.91 & 2.53 & -7.33 & 106.0 & +0.7 \\
\hline
\end{tabular}


The differences between B and BA were even more obvious (see Table 5). In B, ADG was more than $6 \%$ lower in all typical farms than in the baseline. The higher ADG of BA compared to $B$ was a result of the higher daily feed intake of BA compared to B (see Table S1). FCR of B was lower in all typical farms and therefore more efficient compared to the baseline. The fattening period of $B$ was about one week longer in all farms than in the baseline.

Table 5. Impact of boar fattening on performance data of typical German pig fattening farms in relation to baseline (barrows).

\begin{tabular}{ccccccc}
\hline Farm & ADG B (g) & $\boldsymbol{\Delta}$ ADG B (\%) & FCR B & $\boldsymbol{\Delta}$ FCR B (\%) & $\begin{array}{c}\text { Fattening } \\
\text { Period B (days) }\end{array}$ & $\begin{array}{c}\Delta \text { Fattening } \\
\text { Period B (days) }\end{array}$ \\
\hline DE_0_3600 & 779 & -6.20 & 2.69 & -4.46 & 116.2 & +7.2 \\
DE_0_3800 & 721 & -6.04 & 2.66 & -3.97 & 127.7 & +7.7 \\
DE_0_5000 & 765 & -6.24 & 2.70 & -4.26 & 121.6 & +7.6 \\
DE_0_6000 & 748 & -6.16 & 2.78 & -4.47 & 127.9 & +7.9 \\
DE_0_6300 & 823 & -6.12 & 2.61 & -4.40 & 111.9 & +6.9 \\
\hline
\end{tabular}

\subsection{Proportion of Treatment Groups (B, IC, and BA) above Thresholds of Boar Taint Compounds}

All BA and IC were free of boar taint and were below the threshold for the respective androstenone and skatole scenarios. Accordingly, immunocastration was $100 \%$ successful in preventing boar taint. In B, only $8.33 \%$ of the animals were above the threshold of $0.25 \mu \mathrm{g}$ per g liquid fat skatole. Androstenone levels in B were relatively high, and $83.33 \%$ of all B had androstenone levels of over 1 $\mu \mathrm{g}$ per $\mathrm{g}$ liquid fat. Very high levels of androstenone (above $5 \mu \mathrm{g}$ per g liquid fat) were detected in $25 \%$ of all B (see Table 6).

Table 6. Proportion of animals above threshold of corresponding boar taint scenario.

\begin{tabular}{cccccc}
\hline Scenario & $\mathbf{1}$ & $\mathbf{2}$ & $\mathbf{3}$ & $\mathbf{4}$ & $\mathbf{5}$ \\
\hline Group & \multicolumn{5}{c}{ Proportion of Animals Above Thresholds in } \\
\hline B & 8.33 & 100.00 & 83.33 & 58.33 & 25.00 \\
IC & 0.00 & 0.00 & 0.00 & 0.00 & 0.00 \\
BA & 0.00 & - & - & - & - \\
\hline
\end{tabular}

\subsection{Profitability of IC and B in Relation to the Baseline (Barrows)}

Table 7 shows the additional revenue required to reach the level of profitability of the baseline after implementing IC and B. On the basis of the full cost accounting, IC (priced according to the pricing system for barrows) as well as B (priced according to pricing system for boars without price reductions due to boar taint) were less profitable than the baseline in all typical German pig fattening farms (see Table 7). An improvement in FCR for B and IC cannot compensate for decreasing ADG compared to BA. Higher working time requirements for B and IC, additional costs for the vaccine in IC, and price reductions for B due to the pricing system for boars, all result in worse economic efficiency of B and IC compared to the baseline. The results of IC, however, are better than those of B for all farms. For IC, the additional revenue required to be as profitable as the baseline was found to be between EUR 1.44 and 3.20 per $100 \mathrm{~kg}$ hot carcass weight. The size of the farm had no direct influence on the change in profitability. The results for $\mathrm{B}$ were even more obvious. In the long run, an additional revenue of EUR 5.62 up to 7.38 per $100 \mathrm{~kg}$ hot carcass weight was necessary to be as competitive as the baseline scenario. 
Table 7. Additional revenue (EUR) required per $100 \mathrm{~kg}$ hot carcass weight for IC and B to be on the same profitability level as the baseline scenario.

\begin{tabular}{|c|c|c|c|c|c|c|}
\hline \multicolumn{2}{|c|}{ Farm } & DE_0_3600 & DE_0_3800 & DE_0_5000 & DE_0_6000 & DE_0_6300 \\
\hline \multicolumn{2}{|c|}{ Region } & Lower Saxony & Bavaria & North Rhine-Westphalia & Lower Saxony & Schleswig-Holstein \\
\hline \multirow{2}{*}{ Group } & IC & $3.20 €$ & $1.44 €$ & $2.54 €$ & $2.62 €$ & $2.85 €$ \\
\hline & B & $6.90 €$ & $5.62 €$ & $5.71 €$ & $7.38 €$ & $6.95 €$ \\
\hline
\end{tabular}

In addition to Table 7, in Table 8 the extra working time for removing the testes of IC at the slaughter line is calculated but the IC carcasses were still priced on the barrow pricing system. In addition, IC carcasses were also priced on the basis of the pricing system for boars. Unlike B, none of the IC had skatole or androstenone levels above the thresholds, so no further price reductions were applied. The additional costs for removing the testes reduced the profitability of IC compared to the baseline in all typical farms. An application of the boar pricing system for IC lowered the efficiency of IC to the level of $B$, but three out of five typical farms were still more profitable with IC than with B. If we concluded price reductions due to boar taint, the profitability of B declined even more. Discounts for B carcasses above a skatole threshold of $0.25 \mu \mathrm{g} / \mathrm{g}$ liquid fat reduced the profitability of B by around EUR 9.25 to 11.32 per $100 \mathrm{~kg}$ hot carcass weight. The effects of high androstenone levels were even more drastic. An androstenone threshold of $0.5 \mu \mathrm{g} / \mathrm{g}$ liquid fat worsened the operating profitability of B by EUR 75.23 to 84.92 per $100 \mathrm{~kg}$ hot carcass weight. As the threshold values continued to rise and the proportion of $\mathrm{B}$ carcasses above the thresholds decreased, these losses decreased as well. Above an androstenone threshold of $5.0 \mu \mathrm{g} / \mathrm{g}$ liquid fat, the profitability was still EUR 21.45 to 24.81 per $100 \mathrm{~kg}$ hot carcass weight lower compared to the baseline.

Table 8. Additional revenue required per $100 \mathrm{~kg}$ hot carcass weight for IC and B to be on the same profitability level as the baseline scenario, considering different carcass pricing systems and the occurrence of boar taint.

\begin{tabular}{|c|c|c|c|c|c|}
\hline Farm & DE_0_3600 & DE_0_3800 & DE_0_5000 & DE_0_6000 & DE_0_6300 \\
\hline Region & Lower Saxony & Bavaria & North Rhine-Westphalia & Lower Saxony & Schleswig-Holstein \\
\hline \multicolumn{6}{|c|}{ IC } \\
\hline BA pricing & $3.20 €$ & $1.44 €$ & $2.54 €$ & $2.62 €$ & $2.85 €$ \\
\hline +remove testes & $3.54 €$ & $1.79 €$ & $2.88 €$ & $2.95 €$ & $3.20 €$ \\
\hline B pricing & $7.09 €$ & $5.44 €$ & $6.30 €$ & $6.81 €$ & $6.58 €$ \\
\hline \multicolumn{6}{|c|}{ B } \\
\hline B pricing & $6.90 €$ & $5.62 €$ & $5.71 €$ & $7.38 €$ & $6.95 €$ \\
\hline +scenario 1 & $10.48 €$ & $9.39 €$ & $9.25 €$ & $11.32 €$ & $10.41 €$ \\
\hline +scenario 2 & $76.77 €$ & $78.41 €$ & $75.50 €$ & $84.92 €$ & $75.23 €$ \\
\hline +scenario 3 & $64.80 €$ & $66.09 €$ & $63.62 €$ & $71.59 €$ & $63.64 €$ \\
\hline +scenario 4 & $46.54 €$ & $47.41 €$ & $45.70 €$ & $51.57 €$ & 46. $05 €$ \\
\hline +scenario 5 & $22.81 €$ & $22.23 €$ & $21.45 €$ & $24.81 €$ & $22.34 €$ \\
\hline
\end{tabular}

(+) -including further costs; scenarios: including the value of refused carcasses according to various thresholds $(0 €$ per carcass above certain thresholds)—for details see Table 3.

\section{Discussion}

Surgical castration without pain relief is considered unacceptable by society. The fattening of boars and immunocastrates is regarded as animal friendly by some stakeholder groups and discussed as potential alternatives to the fattening of barrows. Both immunocastrates and boars have a better FCR than barrows [32], which is more efficient from an economic point of view, as less feed is needed to produce the same amount of pork. On the other hand, these production systems generate additional production costs due to extra working time and additional vaccination costs [28,33]. In addition, no objective boar taint detection systems are currently in use at slaughterhouses and potential reductions in the value of carcasses by boar taint may reduce the profitability. Because of the small market share of immunocastrates on the German pork market, it is unclear at the moment how these carcasses will 
be priced. This study therefore analyzed the economic impact of immunocastration and boar fattening under different pig carcass pricing systems, including the occurrence of boar taint.

In the present study, feed composition was based on the feed requirements of boars, which means that there is further optimization potential for immunocastrates and barrows, as a less expensive feed with reduced protein and energy content might be appropriate. Such corrections within the calculation would potentially worsen the profitability of pork production with boars even more when compared to immunocastrates or barrows. All animals, irrespective of treatment and weight, were slaughtered in two groups, either at 27 or 28 weeks of age, and not according to the optimal slaughter weight. Similarly, the feeding phases followed the same timeline and were not adapted to weight gain, treatment group, and live weight. This may mask group-specific effects, as the feeding strategy similarly to feed composition should differ between the groups (B, IC, and BA) to optimize performance data, as well as to avoid excessive nitrogen excretion $[34,35]$. Barrows of the used genotype in particular have a higher ADG and would switch earlier to a different feeding period than boars or immunocastrates [32]. In future research, optimal feeding strategies for respective groups should be considered.

The performance data of the experiment show that immunocastrates had higher ADG compared to barrows and boars. This is caused mainly by the performance of immunocastrates in the last feeding period after the second vaccination, which results in an increased feed intake and a higher growth rate [21,32]. Some studies confirm our results and show that immunocastrates grow faster over the entire fattening period than barrows and boars [20,21]. In another study [32], however, barrows revealed a higher ADG than immunocastrates and boars. Such differences may be explained in part by the genotype used in the study. Crossbreds with Belgian Pietrain, for example, have a reduced growth rate before and after the second vaccination than, for example, Duroc crossbreds. In both genotypes, however, the growth rate increased in the two weeks following the second vaccination compared to the growth rate between the first and second vaccination [36]. This may help to explain why, in typical German pig fattening farms, the ADG of barrows is higher than in immunocastrates. Moreover, the effect of slaughter weight has to be considered, as animals are slaughtered at a lower live weight compared to the experimental trials and thus the last feeding period is shorter than in our experiment. In this study, FCR is more efficient in immunocastrates as well as in boars, which is also illustrated by previous studies [20,21,32].

In our study, the carcass data (weight of carcass parts) were adapted to the results obtained via the Auto-FOM III formula. In the case of immunocastrates and boars in particular, however, it can be assumed that this study underestimates the weight of carcass parts (especially the shoulder), since other studies show that carcass yields and the output of valuable meat in immunocastrates is higher than in boars or barrows. Compared to boars, immunocastrates also have higher belly weights [20]. Actual Auto-FOM III data of immunocastrates, however, which would be crucial for future calculations, are not currently available. The dressing percentages of boars and immunocastrates compared to barrows were even worse in this study than in previous studies [20,21], indicating higher economic losses in pork production with boars and immunocastrates compared to the baseline.

All immunocastrates responded well to the vaccine in this study, and no non-responders with boar-tainted carcasses were detected. However, several reviews assume a proportion of non-responders of up to $3 \%[18,37,38]$. This would worsen the profitability of immunocastration, as it would result in a certain number of boar-tainted carcasses above the thresholds. Furthermore, the proportion of tainted boar carcasses is very high in this study and thus reduces the profitability of pork production with boars. An international study by Walstra and co-authors [39], with different genotypes produced under different conditions in Europe, revealed very high androstenone ( $>1 \mu \mathrm{g} / \mathrm{g}$ liquid fat) concentrations in $29 \%$ of the boars, whereas a higher proportion of boars were affected by skatole levels above 0.25 $\mu \mathrm{g} / \mathrm{g}$ liquid fat compared to our study. Nonetheless, more objective boar taint detection systems at the slaughter line are essential in valuing carcasses with regard to boar taint, and would worsen the profitability of boar fattening also for the $29 \%$ of boars affected by boar taint. 
By the end of 2018, Tönnies Holding ApS \& Co. KG introduced a new boar pricing system in Germany. This has even further reduced the economic profitability of boar fattening compared to the baseline [6,28]. The impact of the new boar pricing system on the profitability of immunocastration is also negative and makes the technique economically unviable [28]. In a recent study by Verhaagh and Deblitz [28], the production of pork with immunocastrates was more profitable in all typical German pig fattening farms compared to the baseline (barrows). Although producing immunocastrates generate higher production costs, they were compensated by better FCR, higher ADG, and a shorter fattening period. In the study by Verhaagh and co-authors [28], however, the calculation was based on the ADG values of the entire fattening period, which resulted from higher ADG after the second vaccination. However, in this present study, it could be shown that the last feeding period had a positive effect on the ADG of the entire fattening period, but was economically not sufficient to compensate for the lower ADG of the earlier fattening periods. Furthermore, performance data of this trial declined in relation to the typical farms, as animals were fattened and slaughtered on fixed dates so that greater economic efficiency might be achieved through optimized management of feeding, fattening periods, and age at slaughter.

\section{Conclusions}

This study illustrates that pork production with immunocastrates or boars is economically less profitable under the assumed performance and market criteria compared to the pork production with barrows as the baseline. A change to pork production with boars or immunocastrates would worsen the competitiveness of all typical German pig fattening farms investigated. Better FCR of boars and immunocastrates cannot economically compensate for the higher ADG of barrows. The higher ADG of immunocastrates after the second vaccination is masked in the overall calculation by their lower ADG prior to the second vaccination. The application of the boar pricing system for immunocastrates would further worsen the profitability of immunocastration in comparison to barrows. Boars, however, tend to be less economically viable than immunocastrates, even if both are priced on the boar pricing system. More objective boar taint detection systems at the slaughter line, however, could lead to further price reductions for boars.

Supplementary Materials: The following are available online at http://www.mdpi.com/2077-0472/9/9/204/s1, Table S1: Mean values of animal performance data of the trials.

Author Contributions: Conceptualization, K.K. and M.V.; methodology, K.K. and M.V.; formal analysis, K.K. and M.V.; data curation, K.K. and M.V.; writing-original draft preparation, K.K. and M.V.; writing-review and editing, K.K. and M.V.

Funding: This research is part of the ERA-NET SusAn, project SuSi (co-financed by the European Union's Horizon 2020 Research \& Innovation Program and the German Federal Office for Agriculture and Food), grant number 696231 .

Acknowledgments: The authors thank Volker Stefanski for providing the data of the SuSi project to enable this study; Ulrike Weiler for scientific support and proofreading; Eberhard Reichenecker, Christoph Albert, Nadine Münzenmeier, and Severin Datzer of the experimental unit 'Unterer Lindenhof' for animal care; Christine Frasch for English language corrections; and Nina Batorek-Lukač for analyzing the fat samples from this experiment for androstenone and skatole measurements.

Conflicts of Interest: The authors declare no conflict of interest. The funders had no role in the design of the study; in the collection, analysis, or interpretation of data; in the writing of the manuscript; or in the decision to publish the results.

\section{References}

1. Backus, G.; Higuera, M.; Juul, N.; Nalon, E.; de Briyne, N. Second Progress Report 2015-2017 on the European Declaration on Alternatives to Surgical Castration of Pigs. Available online: https://www.boarsontheway.com/ wp-content/uploads/2018/08/Second-progress-report-2015-2017-final-1.pdf (accessed on 5 August 2019).

2. Fredriksen, B.; Font i Furnols, M.; Lundström, K.; Migdal, W.; Prunier, A.; Tuyttens, F.A.M.; Bonneau, M. Practice on castration of piglets in Europe. Animal 2009, 3, 1480-1487. [CrossRef] [PubMed] 
3. Fredriksen, B.; Johnsen, A.M.S.; Skuterud, E. Consumer attitudes towards castration of piglets and alternatives to surgical castration. Res. Vet. Sci. 2011, 90, 352-357. [CrossRef] [PubMed]

4. Bericht der Bundesregierung über den Stand der Entwicklung Alternativer Verfahren und Methoden zur Betäubungslosen Ferkelkastration Gemäß 21 des Tierschutzgesetzes. Available online: https://www.bmel.de/ SharedDocs/Downloads/Tier/Tierschutz/Regierungsbericht-Ferkelkastration.pdf?_blob=publicationFile (accessed on 5 August 2019).

5. Tierschutzgesetz (Deutschland). Viertes Gesetz zur Änderung des Tierschutzgesetzes Vom 17. Bundesgesetzblatt, Dezember 2018; p. 2586. Available online: https://www.bgbl.de/xaver/bgbl/start.xav? startbk=Bundesanzeiger_BGBl\&start=//*[@attr_id=\%27bgbl118s2586.pdf\%27]\#_bgbl_\%2F\%2F*\%5B \% 40attr_id\%3D\%27bgbl118s2586.pdf\%27\%5D_1568693939165 (accessed on 5 August 2019).

6. Verhaagh, M.; Deblitz, C. Betriebswirtschaftliche Auswirkungen von Alternativen zur betäubungslosen Kastration in Deutschland. Thünen Work. Pap. 2016, 64, 56. [CrossRef]

7. von Borell, E.; Baumgartner, J.; Giersing, M.; Jäggin, N.; Prunier, A.; Tuyttens, F.A.M.; Edwards, S.A. Animal welfare implications of surgical castration and its alternatives in pigs. Animal 2009, 3, 1488-1496. [CrossRef]

8. Weiler, U.; Stefanski, V.; Von Borell, E. Die Kastration beim Schwein-Zielkonflikte und Lösungsansätze aus der Sicht des Tierschutzes. Züchtungskunde 2016, 88, 429-444.

9. Claus, R.; Weiler, U.; Herzog, A. Physiological aspects of androstenone and skatole formation in the boar-A review with experimental data. Meat Sci. 1994, 38, 289-305. [CrossRef]

10. Bonneau, M. Use of entire males for pig meat in the European Union. Meat Sci. 1998, 49, 257-272. [CrossRef]

11. Weiler, U.; Fischer, K.; Kemmer, H.; Dobrowolski, A.; Claus, R. Influence of androstenone sensitivity on consumer reactions to boar meat. In Boar Taint in Entire Male Pigs; Bonneau, M., Lundström, K., Malmfors, B., Eds.; Wageningen Academic Publishers: Wageningen, The Netherlands, 1998; Volume 92, pp. 147-151.

12. Lunde, K.; Egelandsdal, B.; Skuterud, E.; Mainland, J.D.; Lea, T.; Hersleth, M.; Matsunami, H. Genetic Variation of an Odorant Receptor OR7D4 and Sensory Perception of Cooked Meat Containing Androstenone. PLoS ONE 2012, 7, e35259. [CrossRef]

13. Font i Furnols, M.; Gispert, M.; Diestre, A.; Oliver, M.A. Acceptability of boar meat by consumers depending on their age, gender, culinary habits, and sensitivity and appreciation of androstenone odour. Meat Sci. 2003, 64, 433-440. [CrossRef]

14. European Commission. Establishing best Practices on the Production, the Processing and the Marketing of Meat from Uncastrated Pigs or Pigs Vaccinated against Boar Taint (Immunocastrated) 2019. Available online: https://ec.europa.eu/food/sites/food/files/animals/docs/aw_prac_farm_pigs_cast-alt_ establishing-best-practices.pdf (accessed on 5 August 2019).

15. Mathur, P.K.; ten Napel, J.; Bloemhof, S.; Heres, L.; Knol, E.F.; Mulder, H.A. A human nose scoring system for boar taint and its relationship with androstenone and skatole. Meat Sci. 2012, 91, 414-422. [CrossRef]

16. Birkler, R.I.D.; Borggaard; Støie, S.; Lund, B.L.W. Fully automated and rapid at-line method for measuring boar taint related compounds in back fat. Adv. Anim. Biosci. 2018, 9, s33. [CrossRef]

17. Mörlein, J.; Meier-Dinkel, L.; Gertheiss, J.; Schnäckel, W.; Mörlein, D. Sustainable use of tainted boar meat: Blending is a strategy for processed products. Meat Sci. 2019, 152, 65-72. [CrossRef] [PubMed]

18. Čandek-Potokar, M.; Škrlep, M.; Zamaratskaia, G. Immunocastration as Alternative to Surgical Castration in Pigs. Theriogenology 2017, 6, 109-126. [CrossRef]

19. Kress, K.; Millet, S.; Labussière, É.; Weiler, U.; Stefanski, V. Sustainability of Pork Production with Immunocastration in Europe. Sustainability 2019, 11, 3335. [CrossRef]

20. Nautrup, B.P.; Vlaenderen, I.V.; Aldaz, A.; Mah, C.K. The effect of immunization against gonadotropin-releasing factor on growth performance, carcass characteristics and boar taint relevant to pig producers and the pork packing industry: A meta-analysis—ScienceDirect. Res. Vet. Sci. 2018, 119, 182-195. [CrossRef] [PubMed]

21. Batorek-Lukač, N.; Čandek-Potokar, M.; Bonneau, M.; Van Milgen, J. Meta-analysis of the effect of immunocastration on production performance, reproductive organs and boar taint compounds in pigs. Animal 2012, 6, 1330-1338. [CrossRef] [PubMed]

22. Batorek-Lukač, N.; Škrlep, M.; Prunier, A.; Louveau, I.; Noblet, J.; Bonneau, M.; Čandek-Potokar, M. Effect of feed restriction on hormones, performance, carcass traits, and meat quality in immunocastrated pigs. J. Anim. Sci. 2012, 90, 4593-4603. [CrossRef] [PubMed] 
23. Verhaagh, M.; Deblitz, C.; Rohlmann, C. A Standard Operating Procedure to Define Typical Farms. Available online: http://www.agribenchmark.org/fileadmin/Dateiablage/B-Pig/Misc/sop_pig_1801.pdf (accessed on 5 August 2019).

24. Feuz, D.M.; Skold, M.D. Typical Farm Theory in Agricultural Research. J. Sustain. Agric. 1992, 2, 43-58. [CrossRef]

25. Hemme, T. Ein Konzept zur International Vergleichenden Analyse von Politik- und Technikfolgen in der Landwirtschaft; Bundesforschungsanstalt für Landwirtschaft: Braunschweig, Germany, 2000; Volume 215, ISBN 978-3-933140-37-1.

26. Deblitz, C. Modellsteckbrief TIPI-CAL/TYPICROP. Available online: https://www.thuenen.de/de/ infrastruktur/thuenen-modellverbund/modelle/tipi-cal-typicrop/ (accessed on 13 September 2019).

27. Deblitz, C.; Verhaagh, M.; Rohlmann, C. Pig Report 2018: Understanding Agriculture Worldwide. Available online: https://literatur.thuenen.de/digbib_extern/dn060203.pdf (accessed on 5 August 2019).

28. Verhaagh, M.; Deblitz, C. Wirtschaftlichkeit der Alternativen zur Betäubungslosen Ferkelkastration-Aktualisierung und Erweiterung der Betriebswirtschaftlichen Berechnungen. Thünen Work. Pap. 2019, 110, 56. [CrossRef]

29. Imhäuser, R. Ebermäster müssen genauer sortieren. Top. Agrar. 2018, 12, 168-171.

30. Höreth, R. Zur Prüfung des Klassifizierungsgerätes AutoFom-III. Mitteilungsblatt Fleischforschung Kulmbach 2013, 52, 175-178.

31. Vališ, L.; Pulkrábek, J.; Pavlík, J.; Vítek, M.; Wolf, J. Conformation and meatiness of pork belly. Czech J. Anim. Sci. 2005, 50, 116-121. [CrossRef]

32. Pauly, C.; Spring, P.; O’Doherty, J.V.; Ampuero Kragten, S.; Bee, G. Growth performance, carcass characteristics and meat quality of group-penned surgically castrated, immunocastrated (Improvac ${ }^{\circledR}$ ) and entire male pigs and individually penned entire male pigs. Animal 2009, 3, 1057-1066. [CrossRef] [PubMed]

33. de Roest, K.; Montanari, C.; Fowler, T.; Baltussen, W. Resource efficiency and economic implications of alternatives to surgical castration without anaesthesia. Animal 2009, 3, 1522-1531. [CrossRef] [PubMed]

34. Quiniou, N.; Monziols, M.; Colin, F.; Goues, T.; Courboulay, V. Effect of feed restriction on the performance and behaviour of pigs immunologically castrated with Improvac ${ }^{\circledR}$. Animal 2012, 6, 1420-1426. [CrossRef] [PubMed]

35. Schiavon, S.; Bona, M.D.; Carcò, G.; Carraro, L.; Bunger, L.; Gallo, L. Effects of feed allowance and indispensable amino acid reduction on feed intake, growth performance and carcass characteristics of growing pigs. PLoS ONE 2018, 13, e0195645. [CrossRef] [PubMed]

36. Heyrman, E.; Kowalski, E.; Millet, S.; Tuyttens, F.A.M.; Ampe, B.; Janssens, S.; Buys, N.; Wauters, J.; Vanhaecke, L.; Aluwé, M. Monitoring of behavior, sex hormones and boar taint compounds during the vaccination program for immunocastration in three sire lines. Res. Vet. Sci. 2019, 124, 293-302. [CrossRef]

37. Zamaratskaia, G.; Rasmussen, M.K. Immunocastration of Male Pigs-Situation Today. Procedia Food Science 2015, 5, 324-327. [CrossRef]

38. Škrlep, M.; Batorek-Lukač, N.; Prevolnik-Povše, M.; Čandek-Potokar, M. Teoretical and practical aspects of immunocastration. Stočarstvo Časopis za Unapređenje Stočarstva 2014, 68, 39-49.

39. Walstra, P.; Claudi-Magnussen, C.; Chevillon, P.; von Seth, G.; Diestre, A.; Matthews, K.R.; Homer, D.B.; Bonneau, M. An international study on the importance of androstenone and skatole for boar taint: Levels of androstenone and skatole by country and season. Livest. Prod. Sci. 1999, 62, 15-28. [CrossRef]

(C) 2019 by the authors. Licensee MDPI, Basel, Switzerland. This article is an open access article distributed under the terms and conditions of the Creative Commons Attribution (CC BY) license (http://creativecommons.org/licenses/by/4.0/). 